\title{
Bone Health in Patients With Prostate Cancer: An Evidence-Based Algorithm
}

\author{
Eric D. Johnson, MD; Katerina Butler, PharmD; and Sumati Gupta, MBBS
}

Background: The veteran population has an increasingly high number of patients who have either survived, are currently living with, or are being treated for prostate cancer. Survivorship concerns related to the treatment of this disease is a relevant topic in the Veterans Health Administration, given the longevity of life with localized disease treatment and the fairly durable therapies for metastatic disease. Long-term androgen deprivation therapy (ADT) forms the backbone of treatment for advanced and metastatic castration-sensitive prostate cancer.

Observations: The potential bone-health complications resulting from treatment with ADT should be recognized as many patients live for prolonged periods with stable or controlled disease. It is well established that prolonged

\begin{abstract}
ADT can lead to significant bone loss and increased fracture risk, which increases all-cause mortality and disability. Bone-remodeling agents, such as bisphosphonates and receptor-activated nuclear factor $\kappa-B$ ligand inhibitors, are recommended to reduce the risk of fragility fractures in patients at high risk due to diminished bone density while on hormone deprivation therapy for hormone-naive prostate cancer. These agents are also indicated at a higher dose to prevent complications from bone metastases in castrationresistant prostate cancer with bone metastases.
\end{abstract}

Conclusions: This article reviews recent studies on bone health in men with prostate cancer and presents an evidence-based algorithm for bone-health monitoring during treatment and recommended interventions.
Eric Johnson and Sumati Gupta are Oncologists, and Katerina Butler is a Clinical Oncology Pharmacist; all at George E. Wahlen Department of Veterans Affairs Medical Center in Salt Lake City, Utah. Eric Johnson is a Clinical Fellow and Sumati Gupta is an Assistant Professor, both at Huntsman Cancer Institute at the University of Utah in Salt Lake City. Correspondence:

Eric Johnson

(eric.johnson@hci.utah.edu)

Fed Pract. 2021;38 (suppl 3) Published online July 12. doi:10.12788/fp.0155
$\mathrm{P}$ rostate cancer $(P C)$ is the most commonly and newly diagnosed nonskin cancer and the second leading cause of cancer death in men in the United States. About 191,930 cases and about 33,330 deaths from PC were expected for the year $2020 .{ }^{1}$ About 1 in 41 men will die of PC. Most men diagnosed with PC are aged $>65$ years and do not die of their disease. The 5-year survival rate of localized and regional disease is nearly $100 \%$, and disease with distant metastases is $31 \%$. As a result, more than 3.1 million men in the United States who have been diagnosed with $\mathrm{PC}$ are still alive today. ${ }^{1}$ Among veterans, there is a substantial population living with PC. Skolarus and Hawley reported in 2014 that an estimated 200,000 veterans with PC were survivors and 12,000 were newly diagnosed. ${ }^{2}$

In PC, skeletal strength can be affected by several factors, such as aging, malnutrition, androgen-deprivation therapy (ADT), and bone metastasis. ${ }^{3,4}$ In fact, most men can live the rest of their life with $P C$ by using strategies to monitor and treat it, once it shows either radiographic or chemical signs of progression. ${ }^{5}$ ADT is the standard of care to treat hormonesensitive $P C$, which is associated with significant skeletal-related adverse effects (AEs). ${ }^{6,7}$

Men undergoing ADT are 4 times more likely to develop substantial bone deficiency, Shahinian and colleagues found that in men surviving 5 years after PC diagnosis, $19.4 \%$ of those who received ADT had a fracture compared with $12 \%$ in men who did not
$(P<.001)$. The authors established a significant relation between the number of doses of gonadotropin-releasing hormone given in the first 12 months and the risk of fracture. ${ }^{8}$ Of those who progressed to metastatic disease, the first metastatic nonnodal site is most commonly to the bone. ${ }^{9}$ Advanced PC is characterized by increased bone turnover, which further raises concerns for bone health and patient performance. ${ }^{10}$

Skeletal-related events (SREs) include pathologic fracture, spinal cord compression, palliative radiation, or surgery to bone, and change in antineoplastic therapy secondary to bone pain. The concept of bone health refers to the prevention, diagnosis, and treatment of idiopathic, pathogenic, and treatment-related bone loss and delay or prevention of SREs. ${ }^{6,11}$ Guidelines and expert groups have recommended screening for osteoporosis at the start of ADT with bone mineral density testing, ensuring adequate calcium and vitamin $D$ intake, modifying lifestyle behaviors (smoking cessation, alcohol moderation, and regular exercise), and prescribing bisphosphonates or receptor-activated nuclear factor $\kappa-B$ ligand inhibitor, denosumab, for men with osteoporosis or who are at general high-fracture risk. $^{12,13}$ The overuse of these medications results in undue cost to patients as well as AEs, such as osteonecrosis of the jaw (ONJ), hypocalcemia, and bone/joint pains. ${ }^{14-17}$ There are evidence-based guidelines for appropriate use of bisphosphonates and denosumab for delay 
TABLE Prostate Cancer Clinical Trial Findings

\begin{tabular}{|c|c|}
\hline Trials & Study Recommendations \\
\hline \multicolumn{2}{|c|}{ Castration sensitive no bone metastasis } \\
\hline Wirth et $\mathrm{al}^{29}$ & Zoledronic acid use does not prevent bone metastasis \\
\hline James et $\mathrm{al}^{30}$ & Zoledronic acid adds no survival benefit when added to standard therapy \\
\hline Denham et $\mathrm{al}^{31}$ & Zoledronic acid added no benefit with androgen deprivation therapy \\
\hline Dearnaley et $\mathrm{a}^{32}$ & Clodronate does not prevent bone metastasis when compared with placebo \\
\hline Smith et $\mathrm{al}^{33}$ & Denosumab increased bone mineral density, lessened vertebral fractures, no improvement in survival \\
\hline \multicolumn{2}{|c|}{ Castration sensitive with bone metastasis } \\
\hline Smith et $\mathrm{al}^{34}$ & No difference in time to first skeletal-related event \\
\hline Dearnaley et $\mathrm{al}^{32}$ & Clodronate does not increase bone progression-free survival \\
\hline \multicolumn{2}{|c|}{ Castration resistant no bone metastasis } \\
\hline Saad et $\mathrm{al}^{19}$ & Zoledronic acid study closed early due to low event rate \\
\hline Smith et $\mathrm{al}^{37,43}$ & Denosumab use had significant improvement in bone metastasis-free survival \\
\hline \multicolumn{2}{|c|}{ Castration resistant with bone metastasis } \\
\hline Saad et $\mathrm{al}^{44}$ & Zoledronic acid led to decreased rate of skeletal-related events compared with placebo \\
\hline Fizazi et $\mathrm{al}^{40}$ & Denosumab use resulted in significant time increase to first skeletal-related event compa \\
\hline
\end{tabular}

and prevention of SREs in the setting of advanced PC..$^{18}$ These doses also typically differ in frequency to those of osteoporosis. ${ }^{19}$ We summarize the evidence and guidance for health care providers who care for patients with $P C$ at various stages and complications from both disease-related and treatmentrelated comorbidities.

\section{BONE-STRENGTHENING AGENTS}

Overall, there is evidence to support the use of bone-strengthening agents in patients with osteopenia/osteoporosis in the prevention of SREs with significant risk factors for progressive bone demineralization, such as lifestyle factors and, in particular, treatments such as ADT. Bone-remodeling agents for treatment of bony metastasis have been shown to provide therapeutic advantage only in limited instances in the castration-resistant PC (CRPC) setting. Hence, in patients with hormone-sensitive PC due to medication-related AEs, treatment with bone-strengthening agents is indicated only if the patient has a significant preexisting risk for fracture from osteopenia/osteoporosis (Table). The Figure depicts an algorithm for the management of bone health in men with PC who are being treated with ADT.

Denosumab and bisphosphonates have an established role in preventing SREs in metastatic CRPC. ${ }^{20}$ The choice of denosumab or a bisphosphonate typically varies based on the indication, possible AEs, and cost of therapy. There are multiple studies involving initiation of these agents at various stages of disease to improve both time to progression as well as management of SREs. There is a lack of evidence that bisphosphonates prevent metastatic-bone lesions in castration-sensitive PC; therefore, prophylactic use of this agent is not recommended in patients unless they have significant bone demineralization. ${ }^{21,22}$

Medication-induced ONJ is a severe AE of both denosumab and bisphosphonate therapies. Data from recent trials showed that higher dosing and prolonged duration of denosumab and bisphosphonate therapies further increased risk of ONJ by $1.8 \%$ and 
$1.3 \%$, respectively. ${ }^{15}$ Careful history taking and discussions with the patient and if possible their dentist on how to reduce risk are recommended. It is good practice for the patient to complete a dental evaluation prior to starting IV bisphosphonates or denosumab. Dental evaluations should be performed routinely at 3- to 12-month intervals throughout therapy based on individualized risk assessment. ${ }^{23}$ The benefits of using bisphosphonates to prevent fractures associated with osteoporosis outweigh the risk of ONJ in high-risk populations, but not in all patients with PC. A case-by-case basis and evaluation of risk factors should be performed prior to administering bone-modifying therapy. The longterm safety of IV bisphosphonates has not been adequately studied in controlled trials, and concerns regarding long-term complications, including renal toxicity, ONJ, and atypical femoral fractures, remain with prolonged therapy. ${ }^{24,25}$

The CALGB 70604 (Alliance) trial compared 3-month dosing to monthly treatment with zoledronic acid (ZA), showing no inferiority to lower frequency dosing. ${ }^{26} \mathrm{~A}$ Cochrane review of clinical trials found that in patients with advanced PC, bisphosphonates were found to provide roughly 58 fewer SREs per 1000 on average. ${ }^{27}$ A phase 3 study showed a modest benefit to denosumab vs ZA in the CRPC group regarding incidence of SREs. The rates of SREs were 289 of 951 patients in the bisphosphonate group, and 241 of 950 patients in the denosumab group (30.4\% vs $25.3 \%$; hazard ratio [HR], 0.78; 95\% Cl, 0.66-0.93; $P=.005) .{ }^{28} \mathrm{In}$ 2020, the American Society of Clinical Oncology endorsed the Cancer Care Ontario guidelines for prostate bone health care. ${ }^{18}$ Adequate supplementation is necessary in all patients treated with a bisphosphonate or denosumab to prevent treatment-related hypocalcemia. Typically, daily supplementation with a minimum of calcium $500 \mathrm{mg}$ and vitamin D $400 \mathrm{IU}$ is recommended. ${ }^{16}$

\section{BONE HEALTH IN PATIENTS}

\section{Nonmetastatic Hormone-Sensitive PC}

ADT forms the backbone of treatment for patients with local and advanced metastatic castration-sensitive PC along with surgical and focal radiotherapy options. Cancer treatment-induced bone loss is known to occur with prolonged use of ADT. The ZEUS trial found no prevention of bone metastasis in patients with high-risk localized PC with the use of ZA in the absence of bone metastasis. A Kaplan-Meier estimated proportion of bone metastases after a median follow-up of 4.8 years was found to be not statistically significant: $14.7 \%$ in the ZA group vs $13.2 \%$ in the control/placebo group. ${ }^{29}$ The STAMPEDE trial showed no significant overall survival (OS) benefit with the addition of ZA to ADT vs ADT alone (HR, 0.94; 95\% Cl, 0.79-1.11; $P=.45)$, 5 -year survival with ADT alone was $55 \%$ compared to ADT plus ZA with 57\% 5-year survival. ${ }^{30}$ The RADAR trial showed that at 5 years in high Gleason score patients, use of ZA in the absence of bone metastasis was beneficial, but not in low- or intermediate-risk patients. However, at 10-year analysis there was no significant difference in any of the high-stratified groups with or without ZA. ${ }^{31}$

The PR04 trial showed no effect on OS with clodronate compared with placebo in nonmetastatic castration-sensitive $\mathrm{PC}$, with a HR of 1.12 (95\% Cl, 0.89-1.42; $P=.94)$. The estimated 5 -year survival was $80 \%$ with placebo and $78 \%$ with clodronate; 10 -year survival rates were $51 \%$ with placebo and $48 \%$ with clodronate. ${ }^{32}$ Data from the HALT trial showed an increased bone mineral density and reduced risk of new vertebral fractures vs placebo (1.5\% vs $3.9 \%$, respectively) in the absence of metastatic bone lesions and a reduction in new vertebral fractures in patients with nonmetastatic PC. ${ }^{33}$ Most of these studies showed no benefit with the addition of ZA to nonmetastatic PC; although, the HALT trial provides evidence to support use of denosumab in patients with nonmetastatic PC for preventing vertebral fragility fractures in men receiving $A D T$.

\section{Metastatic Hormone-Sensitive PC}

ZA is often used to treat men with metastatic castration-sensitive PC despite limited efficacy and safety data. The CALGB 90202 (Alliance) trial authors found that the early use of ZA was not associated with increased time to first SRE. The median time to first SRE was 31.9 months in the ZA group $(95 \% \mathrm{Cl}, 24.2-40.3)$ and 29.8 months in the placebo group (stratified $\mathrm{HR}, 0.97 ; 95 \% \mathrm{Cl}, 0-1.17$; 1 -sided stratified log-rank $P=.39) .{ }^{34}$ OS was similar between the groups $(\mathrm{HR}, 0.88 ; 95 \% \mathrm{Cl}, 0.70-1.12$; 
$P=.29$ ) as were reported AEs. ${ }^{34}$ Results from these studies suggest limited benefit in treating patients with metastatic hormone-sensitive PC with bisphosphonates without other medical indications for use. Additional studies suggest similar results for treatment with denosumab to that of bisphosphonate therapies. $^{35}$

\section{Nonmetastatic CRPC}

Reasonable interest among treating clinicians exists to be able to delay or prevent the development of metastatic bone disease in patients who are showing biochemical signs of castration resistance but have not yet developed distant metastatic disease. Time to progression on ADT to castration resistance usually occurs 2 to 3 years following initiation of treatment. This typically occurs in patients with rising prostate-specific antigen (PSA). As per the Prostate Cancer Working Group 3, in the absence of radiologic progression, CRPC is defined by a $25 \%$ increase from the nadir (considering a starting value of $\geq 1 \mathrm{ng} / \mathrm{mL}$ ), with a minimum rise of $2 \mathrm{ng} / \mathrm{mL}$ in the setting of castrate serum testosterone $<50 \mathrm{ng} / \mathrm{dL}$ despite good adherence to an ADT regimen, with proven serologic castration either by undetectable or a near undetectable nadir of serum testosterone concentration. Therapeutic implications include prevention of SREs as well as time to metastatic bone lesions. The Zometa 704 trial examined the use of $Z A$ to reduce time to first metastatic bone lesion in the setting of patients with nonmetastatic CRPC. ${ }^{36}$ The trial was discontinued prematurely due to low patient accrual, but initial analysis provided information on the natural history of a rising PSA in this patient population. At 2 years, one-third of patients had developed bone metastases. Median bone metastasis-free survival was 30 months. Median time to first bone metastasis and OS were not reached. Baseline PSA and PSA velocity independently predicted a shorter time to first bone metastasis, metastasis-free survival, and OS. ${ }^{36}$

Denosumab was also studied in the setting of nonmetastatic CRPC in the Denosumab 147 trial. The study enrolled 1432 patients and found a significantly increased bone metastasis-free survival by a median of 4.2 months over placebo (HR, 0.85; $95 \% \mathrm{Cl}, 0.73-0.98$; $P=.03)$. Denosumab significantly delayed
FIGURE Prostate Cancer Bone Health Treatment Algorithm

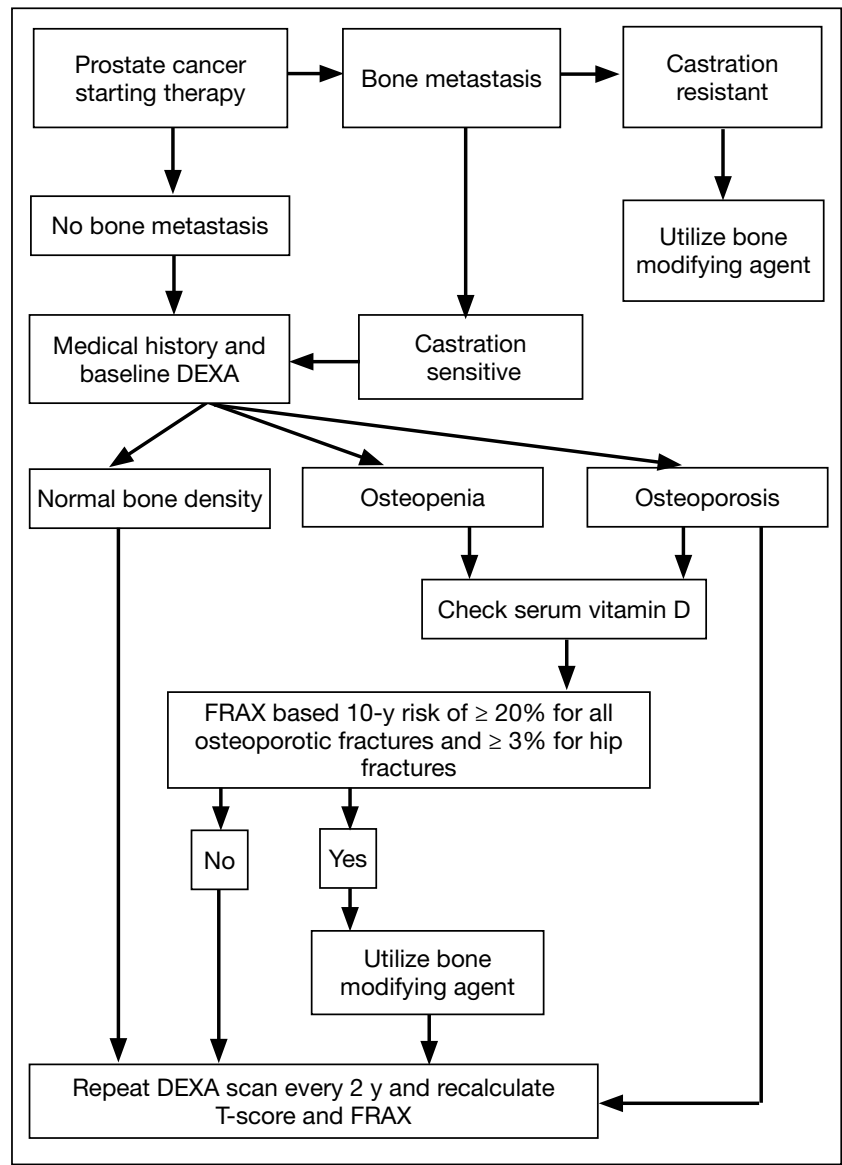

Abbreviations: DEXA, dual energy X-ray absorptiometry; FRAX, fracture risk assessment tool.

time to first bone metastasis (HR, 0.84; 95\% $\mathrm{Cl}, 0.71-0.98 ; P=.03)$. OS was similar between groups (HR, 1.01; 95\% Cl, 0.85-1.20; $P=$ .91). Rates of $A E s$ and serious $A E s$ were similar between groups, except for ONJ and hypocalcemia. The rates of ONJ for denosumab were $1 \%, 3 \%, 4 \%$ in years $1,2,3$, respectively; overall, $<5 \%(n=33)$. Hypocalcemia occurred in $<2 \%$ $(n=12)$ in denosumab-treated patients. The authors concluded that in men with CRPC, denosumab significantly prolonged bone metastasis-free survival and delayed time-to-bone metastasis. ${ }^{37}$ These 2 studies suggest a role of receptor-activated nuclear factor $\mathrm{\kappa}$-B ligand inhibitor denosumab in patients with nonmetastatic CRPC in the appropriate setting. There were delays in bony metastatic disease, but no difference in OS. Rare denosumab treatment-related specific AEs were noted. Hence, denosumab is not recommended for use in this setting. 


\section{Metastatic CRPC}

Castration resistance typically occurs 2 to 3 years following initiation of ADT and the most common extranodal site of disease is within the bone in metastatic PC. Disease progression within bones after ADT can be challenging given both the nature of progressive cancer with osteoblastic metastatic lesions and the prolonged effects of ADT on unaffected bone. The Zometa 039 study compared ZA with placebo and found a significant difference in SREs (38\% and $49 \%$, respectively; $P$.03). No survival benefit was observed with the addition of ZA. Use of other bisphosphonates pamidronate and clodronate did not have a similar degree of benefit. ${ }^{38,39}$

A phase 3 study of 1904 patients found that denosumab was superior to ZA in delaying the time to first on-study SRE (HR, $0.82 ; 95 \% \mathrm{Cl}, 0.71-0.95)$ and reducing rates of multiple SREs (HR, 0.82; 95\% Cl, 0.710.94). ${ }^{40}$ This was later confirmed with an additional study that demonstrated treatment with denosumab significantly reduced the risk of developing a first symptomatic SRE, defined as a pathologic fracture, spinal cord compression, necessity for radiation, or surgery (HR, 0.78; 95\% Cl, 0.66-0.93; $P=.005)$ and first and subsequent symptomatic SREs (rate ratio, $0.78 ; 95 \% \mathrm{Cl}, 0.65-0.92 ; P=.004$ ) compared with ZA. ${ }^{28}$ These findings suggest a continued role of denosumab in the treatment of advanced metastatic CRPC from both control of bone disease as well as quality of life and palliation of cancer-related symptoms.

Radium-223 dichloride (radium-223) is an $\alpha$-emitting radionuclide for treatment of metastatic CRPC with bone metastasis, but otherwise no additional metastatic sites. Radium-223 is a calcium-mimetic that preferentially accumulates into areas of high-bone turnover, such as where bone metastases tend to occur. Radium-223 induces apoptosis of tumor cells through double-stranded DNA breaks. Studies have shown radium-223 to prolong $O S$ and time-to-first symptomatic SRE. ${ }^{41}$ The ERA-223 trial showed that when radium-223 was combined with abiraterone acetate, there was an increase in fragility fracture risk compared with placebo combined with abiraterone. Data from the study revealed that the median symptomatic
SRE-free survival was 22.3 months $(95 \% \mathrm{Cl}$, 20.4-24.8) in the radium-223 group and 26.0 months (21.8-28.3) in the placebo group. Concurrent treatment with abiraterone acetate plus prednisone or prednisolone and radium-223 was associated with increased fracture risk. Osteoporotic fractures were the most common type of fracture in the radium-223 group and of all fracture types, differed the most between the study groups. ${ }^{42}$

\section{CONCLUSIONS}

Convincing evidence supports the ongoing use of bisphosphonates and denosumab in patients with osteoporosis, significant osteopenia with risk factors, and in patients with CRPC with bone metastasis. Bone metastases can cause considerable morbidity and mortality among men with advanced PC. Pain, fracture, and neurologic injury can occur with metastatic bone lesions as well as with ADTrelated bone loss. Prevention of SREs in patients with $P C$ is a reasonable goal in $P C$ survivors while being mindful of managing the risks of these therapies.

\section{Author disclosures}

The authors report no actual or potential conflicts of interest with regard to this article.

\section{Disclaimer}

The opinions expressed herein are those of the authors and do not necessarily reflect those of Federal Practitioner, Frontline Medical Communications Inc., the US Government, or any of its agencies. This article may discuss unlabeled or investigational use of certain drugs. Please review the complete prescribing information for specific drugs or drug combinations - including indications, contraindications, warnings, and adverse effects-before administering pharmacologic therapy to patients.

\section{References}

1. Siegel RL, Miller KD, Jemal A. Cancer statistics, 2020. $C A$ Cancer J Clin. 2020;70(1):7-30. doi:10.3322/caac.21590

2. Skolarus TA, Hawley ST. Prostate cancer survivorship care in the Veterans Health Administration. Fed Pract. 2014;31(8):10-17.

3. Gartrell BA, Coleman R, Efstathiou E, et al. Metastatic prostate cancer and the bone: significance and therapeutic options. Eur Urol. 2015;68(5):850-858. doi:10.1016/j.eururo.2015.06.039

4. Bolla M, de Reijke TM, Van Tienhoven G, et al. Duration of androgen suppression in the treatment of prostate cancer. N Engl J Med. 2009;360(24):2516-2527. doi:10.1056/NEJMoa0810095

5. Welch HG, Albertsen PC. Reconsidering Prostate cancer mortality -The future of PSA screening. N Engl J Med. 2020;382(16):1557-1563. doi:10.1056/NEJMms1914228

6. Coleman R, Body JJ, Aapro M, Hadji P, Herrstedt J; ESMO Guidelines Working Group. Bone health in cancer patients: ESMO Clinical Practice Guidelines. Ann Oncol. 2014;25 (suppl 3):iii124-137. doi:10.1093/annonc/mdu103

7. Saylor PJ, Smith MR. Adverse effects of androgen deprivation therapy: defining the problem and promoting health among men with prostate cancer. J Natl Compr Canc 
Netw. 2010;8(2):211-223. doi:10.6004/jnccn.2010.0014

8. Shahinian VB, Kuo Y-F, Freeman JL, Goodwin JS. Risk of fracture after androgen deprivation for prostate cancer. N Engl J Med. 2005;352(2):154-164. doi:10.1056/NEJMoa041943

9. Sartor O, de Bono JS. Metastatic prostate cancer. N Engl J Med. 2018;378(7):645-657. doi:10.1056/NEJMra1701695

10. Saad F, Eastham JA, Smith MR. Biochemical markers of bone turnover and clinical outcomes in men with prostate cancer. Urol Oncol. 2012;30(4):369-378. doi:10.1016/j.urolonc.2010.08.007

11. Cosman F, de Beur SJ, LeBoff MS, et al; National Osteoporosis Foundation. Clinician's guide to prevention and treatment of osteoporosis. Osteoporos Int 2014;25(10):2359-2381. doi:10.1007/s00198-014-2794-2

12. Alibhai SMH, Zukotynski K, Walker-Dilks $\mathrm{C}$, et al; Cancer Care Ontario Genitourinary Cancer Disease Site Group. Bone health and bone-targeted therapies for prostate cancer: a programme in evidence-based care - Cancer Care Ontario Clinical Practice Guideline. Clin Oncol (R Coll Radiol). 2017;29(6):348-355. doi:10.1016/j.clon.2017.01.007

13. LEE CE. A comprehensive bone-health management approach with men with prostate cancer recieving androgen deprivation therapy. Curr Oncol. 2011;18(4):e163-172. doi:10.3747/co.v18i4.746

14. Kennel KA, Drake MT. Adverse effects of bisphosphonates: Implications for osteoporosis management. Mayo Clin Proc. 2009;84(7):632-638. doi:10.1016/S0025-6196(11)60752-0

15. Saad F, Brown JE, Van Poznak C, et al. Incidence, risk factors, and outcomes of osteonecrosis of the jaw: integrated analysis from three blinded active-controlled phase III trials in cancer patients with bone metastases. Ann Oncol. 2012;23(5):1341-1347. doi:10.1093/annonc/mdr435

16. Body J-J, Bone HG, de Boer RH, et al. Hypocalcaemia in patients with metastatic bone disease treated with denosumab. Eur J Cancer. 2015;51(13):1812-1821. doi:10.1016/j.ejca.2015.05.016

17. Wysowski DK, Chang JT. Alendronate and risedronate: reports of severe bone, joint, and muscle pain. Arch Intern Med. 2005;165(3):346-347. doi:10.1001/archinte.165.3.346-b

18. Saylor PJ, Rumble RB, Tagawa S, et al. Bone health and bone-targeted therapies for prostate cancer: ASCO endorsement of a cancer care Ontario guideline. J Clin Oncol. 2020;38(15):1736-1743. doi:10.1200/JCO.19.03148

19. Saad F, Gleason DM, Murray R, et al; Zoledronic Acid Prostate Cancer Study Group. Long-term efficacy of zoledronic acid for the prevention of skeletal complications in patients with metastatic hormone-refractory prostate cancer. J Nat/ Cancer Inst. 2004;96(11):879882. doi:10.1093/jnci/djh141

20. Saad F, Gleason DM, Murray R, et al; Zoledronic Acid Prostate Cancer Study Group. A randomized, placebocontrolled trial of zoledronic zcid in patients with hormonerefractory metastatic prostate carcinoma. J Nat/ Cancer Inst. 2002;94(19):1458-1468. doi:10.1093/jnci/94.19.1458

21. Aapro M, Saad F. Bone-modifying agents in the treatment of bone metastases in patients with advanced genitourinary malignancies: a focus on zoledronic acid. Ther $A d v$ Urol. 2012;4(2):85-101. doi:10.1177/1756287212441234

22. Cianferotti L, Bertoldo F, Carini M, et al. The prevention of fragility fractures in patients with non-metastatic prostate cancer: a position statement by the international osteoporosis foundation. Oncotarget. 2017;8(43):75646-75663. doi:10.18632/oncotarget.17980

23. Ruggiero S, Gralow J, Marx RE, et al. Practical guidelines for the prevention, diagnosis, and treatment of osteonecrosis of the jaw in patients with cancer. $J$ Oncol Pract. 2006;2(1):7-14. doi:10.1200/JOP.2006.2.1.7

24. Corraini P, Heide-Jørgensen U, Schøodt M, et al. Osteonecrosis of the jaw and survival of patients with cancer: a nationwide cohort study in Denmark. Cancer Med. 2017;6(10):2271-2277. doi:10.1002/cam4.1173

25. Watts NB, Diab DL. Long-term use of bisphosphonates in osteoporosis. J Clin Endocrinol Metab. 2010;95(4):1555-
1565. doi:10.1210/jc.2009-1947

26. Himelstein AL, Foster JC, Khatcheressian JL, et al. Effect of longer interval vs standard dosing of zoledronic acid on skeletal events in patients with bone metastases: a randomized clinical trial. JAMA. 2017;317(1):48-58. doi:10.1001/jama.2016.19425

27. Macherey S, Monsef I, Jahn F, et al. Bisphosphonates for advanced prostate cancer. Cochrane Database Syst Rev. 2017;12(12):CD006250. doi:10.1002/14651858.CD006250.pub2

28. Smith MR, Coleman RE, Klotz L, et al. Denosumab for the prevention of skeletal complications in metastatic castration-resistant prostate cancer: comparison of skeletal-related events and symptomatic skeletal events. Ann Oncol. 2015;26(2):368-374. doi:10.1093/annonc/mdu519

29. Wirth M, Tammela T, Cicalese V, et al. Prevention of bone metastases in patients with high-risk nonmetastatic prostate cancer treated with zoledronic acid: efficacy and safety results of the Zometa European Study (ZEUS). Eur Urol. 2015;67(3):482-491. doi:10.1016/j.eururo.2014.02.014

30. James ND, Sydes MR, Clarke NW, et al; STAMPEDE Investigators. Addition of docetaxel, zoledronic acid, or both to first-line long-term hormone therapy in prostate cancer (STAMPEDE): survival results from an adaptive, multiarm, multistage, platform randomised controlled trial. Lancet. 2016;387(10024):1163-1177. doi:10.1016/S0140-6736(15)01037-5

31. Denham JW, Joseph D, Lamb DS, et al. Short-term androgen suppression and radiotherapy versus intermediate-term androgen suppression and radiotherapy, with or without zoledronic acid, in men with locally advanced prostate cancer (TROG 03.04 RADAR): 10-year results from a randomised, phase 3, factorial trial. Lancet Oncol. 2019;20(2):267-281. doi:10.1016/S1470-2045(18)30757-5

32. Dearnaley DP, Mason MD, Parmar MK, Sanders K, Sydes MR. Adjuvant therapy with oral sodium clodronate in locally advanced and metastatic prostate cancer: long-term overall survival results from the MRC PR04 and PR05 randomised controlled trials. Lancet Oncol. 2009;10(9):872876. doi:10.1016/S1470-2045(09)70201-3

33. Smith MR, Egerdie B, Toriz NH, et al; Denosumab HALT Prostate Cancer Study Group. Denosumab in men receiving androgen-deprivation therapy for prostate Cancer. N Engl J Med. 2009;361(8):745-755. doi:10.1056/NEJMoa0809003

34. Smith MR, Halabi S, Ryan CJ, et al. Randomized controlled trial of early zoledronic acid in men with castrationsensitive prostate cancer and bone metastases: results of CALGB 90202 (alliance). J Clin Oncol. 2014;32(11):1143 1150. doi:10.1200/JCO.2013.51.6500

35. Kozyrakis D, Paridis D, Perikleous S, Malizos K, Zarkadas A, Tsagkalis A. The current role of osteoclast inhibitors in patients with prostate cancer. Adv Urol. 2018;2018:1525832. doi:10.1155/2018/1525832

36. Smith MR, Kabbinavar F, Saad F, et al. Natural history of rising serum prostate-specific antigen in men with castrate nonmetastatic prostate cancer. J Clin Oncol. 2005;23(13):2918-2925. doi:10.1200/JCO.2005.01.529

37. Smith MR, Saad F, Coleman R, et al. Denosumab and bone-metastasis-free survival in men with castration-resistant prostate cancer: results of a phase 3 , randomised, placebo-controlled trial. Lancet. 2012;379(9810):39-46. doi:10.1016/S0140-6736(11)61226-9

38. Small EJ, Smith MR, Seaman JJ, Petrone S, Kowalski MO. Combined analysis of two multicenter, randomized, placebo-controlled studies of pamidronate disodium for the palliation of bone pain in men with metastatic prostate cancer. J Clin Oncol. 2003;21(23):4277-4284. doi:10.1200/JCO.2003.05.147

39. Ernst DS, Tannock IF, Winquist EW, et al. Randomized, double-blind, controlled trial of mitoxantrone/prednisone and clodronate versus mitoxantrone/prednisone and placebo in patients with hormone-refractory prostate cancer and pain. J Clin Oncol. 2003:21(17):33353342. doi:10.1200/JCO.2003.03.042 
40. Fizazi K, Carducci M, Smith M, et al. Denosumab versus zoledronic acid for treatment of bone metastases in men with castration-resistant prostate cancer: a randomised, double-blind study. Lancet. 2011;377(9768):813-822. doi:10.1016/S0140-6736(10)62344-6

41. Parker C, Nilsson S, Heinrich D, et al; ALSYMPCA Investigators Alpha emitter radium-223 and survival in metastatic prostate cancer. $N$ Engl $J$ Med. 2013;369(3):213-223. doi:10.1056/NEJMoa1213755

42. Smith M, Parker C, Saad F, et al. Addition of radium-223 to abiraterone acetate and prednisone or prednisolone in patients with castration-resistant prostate cancer and bone metastases (ERA 223): a randomised, double-blind, placebo-controlled, phase 3 trial. Lancet Oncol. 2019;20(3):408-419. doi:10.1016/S1470-2045(18)30860-X

43. Smith MR, Saad F, Shore ND, et al. Effect of denosumab on prolonging bone-metastasis-free survival (BMFS) in men with nonmetastatic castrate-resistant prostate cancer (CRPC) presenting with aggressive PSA kinetics. J Clin Oncol. 2012;30(5_suppl):6-6.

44. Saad F, Gleason DM, Murray R, et al; Zoledronic Acid Prostate Cancer Study Group. A randomized, placebo-controlled trial of zoledronic acid in patients with hormone-refractory metastatic prostate carcinoma. J Natl Cancer Inst. 2002;94(19):1458-1468. doi:10.1093/jnci/94.19.1458 